\title{
Bitkilerin Abiyotik Stres Koşullarıyla Başa Çıkmasına Yardımcı Strigolaktonlar
}

\author{
İlkay Yavaş ${ }^{*}$, Yelda Emek $^{2}$ \\ ${ }^{1 *}$ Aydın Adnan Menderes Üniversitesi, Koçarlı Meslek Yüksekokulu, Bitkisel ve Hayvansal Üretim Bölümü, Aydın, Türkiye, (ORCID: 0000-0002-6863-9631), \\ iyavas@adu.edu.tr \\ ${ }^{2}$ Aydın Adnan Menderes Üniversitesi, Ziraat Fakültesi, Tarımsal Biyoteknoloji Bölümü, Aydın, Türkiye (ORCID: 0000-0003-1095-3908), yelda@adu.edu.tr
}

(İlk Geliş Tarihi 14 Ekim 2021 ve Kabul Tarihi 24 Aralık 2021)

(DOI: 10.31590/ejosat.1009438)

ATIF/REFERENCE: Yavaş, İ. \& Emek, Y. (2021). Bitkilerin Abiyotik Stres Koşullarıyla Başa Çıkmasına Yardımcı Strigolaktonlar. Avrupa Bilim ve Teknoloji Dergisi, (31), 686-690.

Öz

Bitki hormonları ya da fitohormonlar, bitkilerde az miktarda bulunan, doğal olarak oluşan, çevresel streslere (abiyotik/biyotik) karşı dayanıklılığın oluşmasına etki eden, bitki büyümesi, gelişimi, çevre ve diğer organizmalar ile bitki arasındaki etkileşimde önemli role sahip olan organik maddelerdir. Köklerde sentezlenip, sürgünlere taşınımı gerçekleşen, karotenoidlerden türevlenen strigolaktonlar (SL) ise, bitkide sürgün dallanmasını baskılayan, yaşlanma, kök büyümesi, besin elementi eksikliğinde, mineral alımını artırmak için Arbüsküler Mikorizal Fungus (AMF) ile simbiyotik ilişkiyi teşvik eden, bunun sonucunda su ve mineral madde alımını artıran yeni bir bitki hormonu olarak bilinmektedir. Ayrıca kuraklık, sıcaklık, ağır metal, tuz stresi ve mineral yetersizliği gibi çeşitli abiyotik stres koşullarında da etkili olmaktadır. Su stresi altında, SL'lar sürgün büyümesini engellerken (sitokinin ile etkileşim), su alımını artırmak için, yan kök gelişimini teşvik etmektedir. Absisik asit ile etkileşimde, SL'lar stoma yoğunluğunu düzenlemekte, tohum dormansisini ortadan kaldırarak, çimlenmeyi artırmaktadır. AMF ile olan birliktelik, bitkide strigolakton üretimine de etkide bulunarak, tuz stresinin etkilerini hafifletebilmektedir. Besin elementi, özellikle azot ve fosfor eksikliğinde, bitkide sürgün dallanmasının baskılanmasına yol açan ve simbiyotik ilişkiyi teşvik eden yüksek miktarda SL üretimine neden olmaktadır. AMF, hifler aracılığı ile suyun ve azot, fosfor gibi besin maddelerinin teminini sağlamaktadır. Ağır metal stresi koşullarında, SL'ların dışarıdan uygulanması, ağır metal kaynaklı oksidatif stresi azaltmakta, klorofil miktarını, fotosentezi, antioksidan enzim aktivitelerini artırmakta, lipid peroksidasyonu ile birlikte Reaktif oksijen türlerinin (ROS) seviyesini azaltmakta ve bitki büyümesini teşvik etmektedir. Böylece bitkiler, ağır metal ile bulaşık alanlarda fitohormonları dengeleyerek daha iyi hayatta kalabilmektedir.

Anahtar Kelimeler: Abiyotik stres, AMF, Fotosentez, Strigolakton, Sürgün.

\section{Strigolactones Help Plants to Cope with Abiotic Stress Conditions}

\begin{abstract}
Plant hormones or phytohormones are organic substances that are found in small amounts in plants occur naturally, have an important role in plant growth, development, the environment and the interaction between the plant and other organisms. On the other hand, strigolactones (SL) derived from carotenoids, which are synthesized in the roots and transported to the shoots, suppress shoot branching in the plant. It is known as a new plant hormone that increases water and mineral substance intake by promoting symbiotic relationship with Arbuscular Mycorrhizal Fungi (AMF) to increase mineral substance intake in senescence, root growth, nutrient deficiency. It is also effective in various abiotic stress conditions such as drought, heat, heavy metal, salt stress and mineral deficiency. Under water stress, SLs inhibit shoot growth (interaction with cytokinin) while promoting lateral root growth to increase water uptake. In interaction with abscicic acid, SLs regulate stomatal density, remove seed dormancy and increase germination. The association with AMF can alleviate the effects of salt stress by affecting the production of strigolactone in the plant. The nutrient element, especially nitrogen and phosphorus deficiency, causes the production of high amount of SL, which causes the suppression of shoot branching and promotes the symbiotic relationship in the plant. AMF provides the water and nutrients such as nitrogen and phosphorus through hyphae. Under heavy metal stress conditions, external application of SLs reduces heavy metal-induced oxidative stress, increases the amount of chlorophyll, photosynthesis, antioxidant enzyme activities, decreases the level of reactive oxygen species (ROS) together with lipid peroxidation and promotes plant growth. Thus, plants can survive better in heavy metalcontaminated areas by balancing phytohormones.
\end{abstract}

Keywords: Abiotic stress, AMF, Photosynthesis, Strigolactone, Shoot

*Sorumlu Yazar: iyavas@adu.edu.tr 


\section{Giriş}

\subsection{Strigolaktonlar (SL)}

Bitkilerde büyüme ve gelişme olaylarında iç ve dış faktörler birlikte rol alırlar (Kumlay ve Eryiğit, 2011). Bitkiler değişen çevre koşullarına uyum sağlamak için büyüme, gelişme ve metabolizmayı değiştirerek esneklik geliştirmişlerdir. $\mathrm{Bu}$ esnekliğin sağlanmasında bitki büyüme hormonlarının da rol aldığı bilinmektedir (Gözükırmızı ve Karlık, 2019). Günümüze kadar oksin, brassinosteroid, sitokinin, giberellinler, etilen, jasmonik asit, strigolakton (SL), absisik asit ve salisilik asit adı verilen dokuz farklı bitki hormonu keşfedilmiştir (Druege ve ark., 2016; Verma ve ark., 2016)

Strigolaktonlar, sürgün dallanmasını engelleyen, gövde kalınlaşmasını, yaprak yaşlanmasını, kök tüylerinin uzamasını ve birincil kök büyümesini, lateral kök gelişimi ve adventif kök oluşumunu, bitki-toprak mikroorganizmaları arasındaki simbiyotik ilişkiyi teşvik etmek amacıyla üretilen yeni bir bitki hormonu olarak tanımlanmıştır (Smith, 2014; Umehara ve ark., 2008; García-Garrido ve ark., 2009; Umehara, 2011; Al-Babili ve Bouwmeester, 2015; Ueda ve, Kusaba, 2015; Kopta ve ark., 2017; Waters ve ark., 2017). Ayrica besin elementi eksikliklerinde (azot ve fosfor) üretimi artmakta ve çevresel koşullara adaptasyonu sağlamaktadır (Umehara, 2011).

Köklerde üretilen strigolaktonlar, ksilemler yoluyla bitkinin üst kısımlarına taşınır ve lateral tomurcukların büyümesini engeller (Ferguson ve Beveridge, 2009). Strigolaktonlar, sürgünlere uygulandığında sürgün uzunluğunu kısaltır. Oksinler, lateral tomurcuklar üzerindeki engelleyici etkiyi strigolakton yoluyla gerçekleştirir (Brewer ve ark., 2009).

Strigolaktonlar, terpenler ya da izoprenler adı verilen yap1 taşlarından oluşan karotenoidlerden üretilmektedir. Karotenoidler ve dolayisiyla strigolaktonlar bu nedenle terpenoidler veya izoprenoidler olarak tanımlanabilmektedir (Smith, 2014). SL'lerin biyosentezi $\beta$-karotenlerden köken alır. Sentez yeri sitoplazma ve plastidlerdir. Plastidlerde, DWARF27 (D27), Karotenoid Cleavage Dioxygenaz7 (CCD7) ve Karotenoid Cleavage Dioxygenaz8 (CCD8) enzimlerinin tepkimeleri ile karlakton (CL) molekülü sentezlenir. Sentezlenen CL sitoplazmaya taşınır ve orada MAX1 enzimiyle ya strigol ve orobankol gibi moleküllere dönüşür ya da Arabidopsis thaliana bitkisinde karlaktonik asit üzerinden yine bir SL benzeri bir bileşik olan metil karlaktona dönüştür. SL'lerin merkezi $\mathrm{ABC}$ olarak nitelendirilen bir trisiklik laktondur. Bu taşıııcı moleküle enol eter bağı ile bağlanan ve D halkası olarak adlandırılan 9 $\alpha, \beta$-doymamıs furaron bağlanmıştır. Bunlar iki tipe ayrılır: strigol ve orobankol (Lopez- Obando ve ark, 2015). Strigaloktonların biyosentezi ile ilgili olarak çalışmalar halen devam etmektedir. En son önerilen SL biyosentez yolağı ise Mashiguchi ve ark. (2000) tarafindan önerilmiştir (Şekil 1).

SL'ların, sürgün dallanmasını engellemesi nedeniyle, bahçe bitkilerinde dal sayısını belirlemede etkili olmaktadır. Sentetik strigolaktonun (GR24) ekzojen olarak uygulanmas1, Arabidopsis'in çiçek salkımlarında, bezelye ve okaliptüs bitkilerinin gövdelerinde sekonder büyümeyi artırmıştır. Sekonder büyümenin neden olduğu bu biyomas artışı ile gövde daha da kuvvetlenerek, tahıllarda yatmanın önüne geçilebilir (Takahashi ve Asami, 2018).

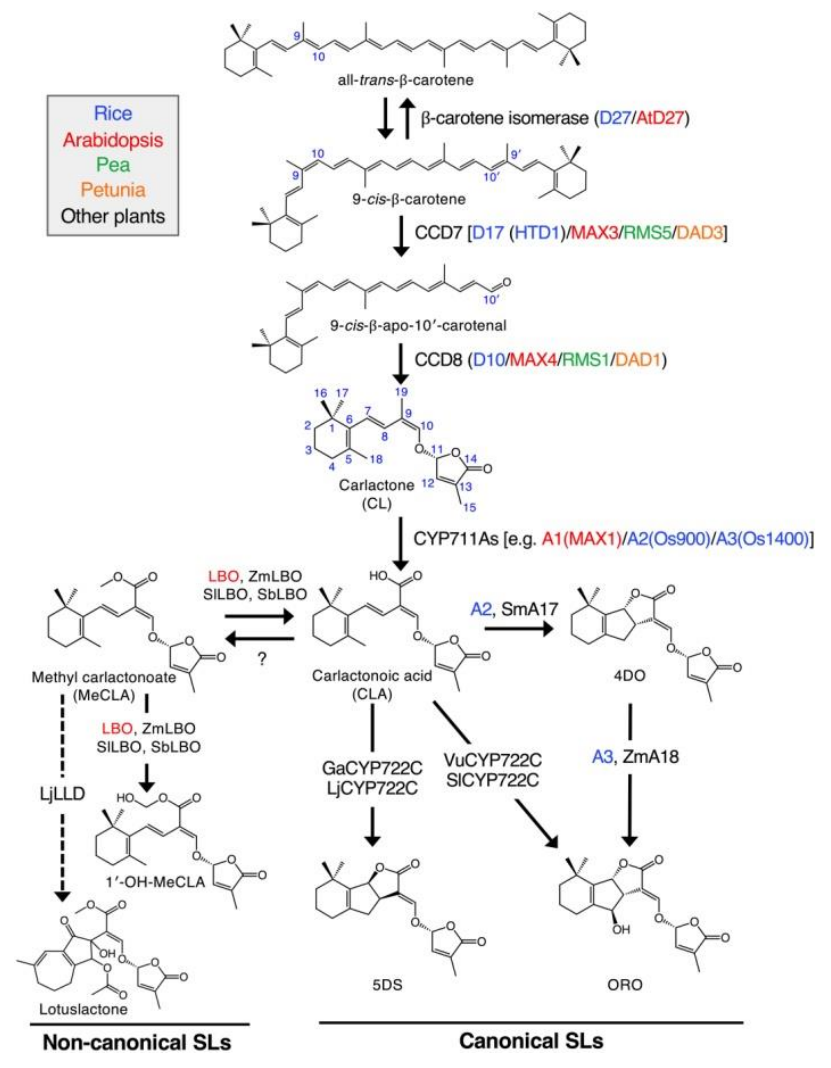

Şekil 1. Strigolaktonların Biyosentez yolağı (Mashiguchi ve ark., 2000)

Strigolaktonlar, bitki fizyolojisi üzerine sinyal molekülü, ayrıca bitki gelişimi ve büyüme düzenleyicisi olarak önemli role sahiptir. SL, fosfat eksikliği koşullarında, yanal kök oluşumunu uyararak, kök yapısını etkilemekte; fakat fosfat düzeyinin yeterli olması durumunda, A. thaliana'da bu süreci baskılamaktadır. Strigolaktonlar ayrıca, Arbüsküler mikorizal funguslarda (AMF) presimbiyotik hiflerin dallanmasını ya da parazitik bitki tohumlarının çimlenmesini teşvik ederek sinyal görevi görmektedir. Türe bağlı olarak değişmekle birlikte, fosfor eksikliğinde, AMF ile simbiyotik ilişkiyi artırmak için, köklerden strigolakton salgısı artı̧ göstermektedir (Carvalhais ve ark., 2019).

Strigolaktonlar, cadı otu veya süpürge otu gibi uzun yıllar dormansi durumunda olan parazit bitkilerin çimlenmesini uyarmaktadır. Ayrıca diğer bitki büyüme düzenleyicilerini de etkileyerek, tohumlarda dormansi/çimlenmeyi düzenlemektedir. Toh ve ark. (2012), SL'ların Arabidopsis'te tohum çimlenmesini düzenleyen gibberellik asit (GA) ile sinerjik etki gösterdiğini vurgulamışlardır. SL'lar ayrıca oksin hormonunun taşınmasını da engelleyerek, bitkilerde dallar arasındaki rekabeti artırmaktadır (Önay, 2019).

\subsection{Abiyotik Stres ve Strigolaktonlar (SL)}

Bitki hormonlarının yeni bir sınıfi olan strigolaktonlar, bitki biyotik ve abiyotik stres tepkilerinde önemli rol oynamaktadır (Saeed ve ark., 2017; Banerjee ve Bhadra, 2020).

Arabidopsis bitkisinde SL-eksik mutantlara, dışarıdan SL uygulaması, kuraklık stresinin etkilerini hafifletmiştir. Kuraklığa duyarlı genotiplerde ise, stomatal iletkenliğini artırarak, absisik asit (ABA) nedeniyle meydana gelen stoma kapanması azalmıştır (Van Ha ve ark., 2014). SL'ler ayrıca bitkilerde tomurcuk büyümesini düzenleyen sitokinin ile de antagonistik olarak hareket etmektedir. 
Tuz stresi koşullarında, Pancratium maritimum bitkisine GR24 ön uygulamasının, antioksidan savunma sistemini uyararak, tolerans seviyesini artırabilme potansiyeli olduğu saptanmıştır (Gök Özel, 2018). Benzer şekilde soya fasulyesine tuzlu koşullarda $5 \mu \mathrm{M}$ GR24 uygulaması, herhangi bir etkide bulunmazken, strigolakton seviyesinin artmas1 (10 $\mu \mathrm{M}$ GR24), stresin oluşturduğu zararın hafiflemesine neden olmuştur (Demirbaş ve ark., 2015). Ling ve ark. (2020), çeltikte tuz stresi koşullarında strigolakton uygulamasının, bitki boyu, kök uzunluğu, süperoksit dismutaz, peroksidaz seviyesini artırdığını fakat malondialdehit miktarını azalttığını vurgulamışlardır. Bu nedenle strigolakton (GR24) konsantrasyonları, çeltik fidelerindeki tuz stresinin zararını hafifletmekte ve yüksek tuz koşullarına uyumu artırmaktadır. Tuz stresi koşullarında buğday bitkisine GR24 ön uygulaması ise, askorbat glutatyon döngüsü enzim sistemini uyararak tuz koşullarına toleransı sağlamıştır (Önay, 2019). Tuz koşullarında, GR24 uygulamasına bağlı olarak buğday genotiplerinin, net $\mathrm{CO}_{2}$ asimilasyon oranı da artmıştır (Kausar ve Shahbaz, 2017). Bir başka çalışmada ise, tuz stresinde ayçiçeğine GR24 uygulamasının, kök ve sürgün büyümesini olumlu yönde etkilediği, tuzun zararlı etkilerini hafiflettiği, fakat fotosentetik pigmentler üzerine çok etkili olmadığ 1 gözlenmiştir. Yapraktan uygulanan GR24'ün osmotik potansiyel ve nisbi nem içeriğini artırdığı bildirilmiştir (Sarwar ve Shahbaz, 2019). Benzer şekilde, Zulfiqar ve ark. (2020) tuz stresi altında ayçiçeğine GR24 uygulamasının, tuzun zararlı etkilerini azalttığını vurgulamışlardır. Ma ve ark. (2017), tuz stresine maruz kalan Brassica napus bitkilerinin GR24 uygulaması ile bitkide büyüme ve fotosentezin olumlu yönde etkilendiğini ifade etmişlerdir.

Kurak koşullar altında, dışarıdan SL uygulaması, membran lipid peroksidasyonunun azalmasına neden olmuş, buğdaydaki antioksidan enzimlerin aktivitesini, fotosentetik pigment içeriğini iyileştirmiş ve böylece buğday verimini artırmıştır (Wang ve ark., 2021). Arabidopsis'te, kurak ve tuzluluğa tolerans SL aracılığı ile gözlemlenmiştir (Van Ha ve ark., 2014). Benzer durum domates bitkisinde de ortaya çıkmıştır (Visentin ve ark., 2016). GR24 uygulaması buğdayda katalaz (CAT) aktivitesini artırmış, hidrojen peroksit $\left(\mathrm{H}_{2} \mathrm{O}_{2}\right)$ birikimini azaltmış, tuzluluğa duyarlı genotipin antioksidan enzim tepkilerini değiştirerek, tuz toleransının artmasına neden olmuştur (Kürtür, 2018).

Ağır metal toksisitesini azaltmada fitohormonlar kullanılmaktadır (Piotrowska-Niczyporuk ve ark., 2012; BuckerNeto ve ark., 2012). Strigolaktonlar çeltik köklerinde arsenat alımını, glutatyon-biyosentezini ve antioksidan savunma tepkilerini düzenleyerek arsenik stresinin azaltılmasında rol oynamaktadır (Mostofa ve ark., 2021).

Kadmiyum (Cd) stresi altında, arpa bitkilerine GR24 uygulamas1, besin elementlerini dengeleyerek, reaktif oksijen türlerini dolaylı olarak ortadan kaldırmakta ve bitkileri toksik oksidasyondan korumaktadır. $\mathrm{Bu}$ nedenle, $\mathrm{Cd}$ kirliliğin azaltılmasına katkıda bulunabileceği vurgulanmaktadır (Qiu ve ark., 2021). Cd toksisitesinde, dişarıdan GR24 uygulaması, Panicum virgatum bitkisinde $\mathrm{Cd}$ konsantrasyonunda azalmaya neden olmuş fakat $\mathrm{Fe}$ ve $\mathrm{Zn}$ seviyeleri yükselmiştir. Stres, doğrudan SL biyosentezini, bunun sinyalini ya da diğer bitki hormonları, özellikle ABA ile etkileşime etkide bulunabilmektedir. Kadmiyum toksisitesinde dişarıdan GR24 uygulaması sonucu, toksisitedeki azalma, ekzojen GR24'ün endojen SL'lerin içeriğini, demir, çinko, mangan ve bakır alımını artırması ve sürgünlerde birikiminin önlenmesinden kaynaklanabilir. Böylelikle klorofil içeriği, fotosentez ve bitki büyümesi olumlu yönde etkilenmektedir (Tai ve ark., 2017).

Köklerdeki SL seviyeleri, kök çevresindeki besin maddeleri, özellikle azot (N) ve fosfor (P) seviyeleri tarafından belirlenmektedir. SL üretimi, $\mathrm{N}$ ve P'un dışında, kükürt (S) eksikliğinde de açığa çıkmakta, sürgün dallanması engellenmekte, yaprak yaşlılığ Yonca, buğday, sorgum, misır ve çeltik bitkileri fosfor eksikliğinde yükssek oranda SL üretmektedir. Çeltik bitkisinde S, $\mathrm{N}$ ve $\mathrm{P}$ eksikliği durumunda, hücre içi SL seviyeleri artış göstermekte, yaprak yaşlanması ise hızlanmaktadır. Bu nedenle, SL'ların, P eksikliğinde etkili bir şekilde kullanılabileceği vurgulanmaktadır. Fĭg, buğday, sorgum, misır ve çeltik bitkilerinde azot eksikliğinde de SL seviyelerinin artış gösterdiği gözlenmiştir. Beyaz acı baklada ise, $\mathrm{N}$ ve $\mathrm{P}$ eksikliklerinde, köklerdeki SL seviyelerinin değişmediği ortaya çıkmıştır (Shindo ve ark., 2021). Bitki, yetersiz besin elementi gibi çeşitli olumsuz çevre koşulları ile karşılaştığında, strigolakton seviyesi artmaktadır. Bununla ilgili en fazla çalışılan konu fosfat eksikliği olmuştur (Brewer ve ark., 2013). Düşük fosfat koşullarında yetiştirilen, kırmızı yoncada strigolakton seviyelerinin arttığı saptanmıştır (Yoneyama ve ark., 2007). Bu şartlar altında büyüme gösteren bitkilerde, sürgün dallanması baskılanmakta, yanal kök oluşumu ve kök tüy yoğunluğu artmaktadır. Nitrat eksikliği ise bitki büyümesi üzerinde fosfata benzer bir etkiye sahip olup, sürgündeki fosfat seviyelerine etki ederek, strigolakton eksüdasyonunu değiştirebilmektedir. Fosfat eksikliğinde de, bazı Arabidopsis ekotiplerinde birincil kök oluşumu engellenirken, çeltik bitkisinde teşvik edilmektedir. $\mathrm{Bu}$ nedenle, strigolaktonlar kökteki hormonlar arasındaki karmaşık etkileşimi anlamada önemli bir bağlantı oluşturarak, çevreye, özellikle besin elementi içeriğine tepki olarak birincil ve yan köklerin farklı tepkilerini ortaya koyabilir (Brewer ve ark., 2013). Strigolaktonlar (SL) ile fosfat kullanımı arasında bir ilişki bulunmaktadır. Düşük fosfat seviyeleri SL metabolizmasını, büyümeyi düzenlemekte, çevreden fosfat alımını optimize etmek için kök ve sürgün yapısını iyileştirmektedir. Fosfor (P) eksikliği koşullarında domates köklerinde strigolakton hormonları birikmekte ve bitki fenotipinde değişikliğe neden olmaktadır. Sürekli P eksikliği koşullarında ise strigolakton uygulaması yapılmadığı takdirde, domateste kök büyümesi azalma göstermektedir (Santaro ve ark., 2020). Fosfor eksikliği gözlenen $A$. thaliana bitkilerinde strigolaktonlar, yan kök gelişimini ve kök tüyü oluşumunu teşvik ederek, kök yüzey alanını artırmakta, birincil kök büyümesini engellemekte, tomurcuk gelişimini baskılamaktadır (Czarnecki ve ark., 2013). Sentetik strigolaktan olan GR24 uygulaması, Cd içeriğini azaltıp, besin elementlerini dengeleyip, reaktif oksijen türlerini dolaylı olarak ortadan kaldırarak, arpayı toksik oksidasyondan korumuş ve $\mathrm{Cd}$ kirliliği riskinin azaltılmasına etkide bulunmuştur (Qiu ve ark., 2021). GR24'ün fosfat eksikliğinde uygulanması, yabani bitkilerin yan kök sayılarını artırırken, yüksek fosfat koşullarında, kök oluşumunu baskılayarak, yanal kök yoğunluğunun azalmasına neden olmaktadır (Ruyter-Spira ve ark., 2011). Ayrıca, Arabidopsis ve çeltikte düşük fosfat, strigolakton seviyesinin artmasına, tomurcuklarda büyümenin azalmasına neden olmuştur (Umehara ve ark., 2010; Kohlen ve ark., 2011).

Nodül oluşturan baklagillerde $\mathrm{SL}$ üretimi sadece $\mathrm{P}$ noksanlığında teşvik edilirken, baklagil olmayan mikotropik bitkilerde $\mathrm{N}$ noksanlığında da meydana gelmektedir. Bu nedenle, SL birikiminin düzenlenmesinin başlangıçta farklı bitki 
türlerinin besin edinme stratejisiyle bağlantılı olduğu öne sürülmektedir (Xie ve ark., 2010).

\section{Sonuç}

Bitkide olumsuz çevre koşulları abiyotik strese neden olmaktadır. Strigolaktonlar ise, karotenoid türevli olup, bitkide abiyotik stresi düzenlediği bilinen, endojen ve ekzojen sinyal

\section{Kaynakça}

Al-Babili, S., Bouwmeester, H.J. (2015). Strigolactones, a novel carotenoid-derived plant hormone. Annu Rev Plant Biol, 66:161-186.

Banerjee, P., Bhadra, P. (2020). Formulation of Anti-microbial and Anti-aging Oil from Natural Resources for Topical Application. International Journal of Botany Studies, 5(3): 279-284

Brewer, P.B., Dun, E.A., Ferguson, B.J., Rameau, C., Beveridge, C.A. (2009). Strigolactone acts downstream of auxin to regulate bud outgrowth in pea and arabidopsis. Plant Physiology 150, 482-493.

Brewer, P.B., Koltai, H., Beveridge, C.A. (2013). Diverse roles of strigolactones in plant development. Mol. Plant, 6: 18-28.

Bucker-Neto, L., Paiva, A.L.S., Machado, R. D., Arenhart, R.A., MargisPinheiro, M. (2017). Interactions between plant hormones and heavy metals responses. Genetics and Molecular Biology. 40: 373-386.

Carvalhais, L.C., Rincon-Florez, V.A., Brewer, P.B., Beveridge, C.A., Dennis, P.G., Schenk, P.M. (2019). The ability of plants to produce strigolactones affects rhizosphere community composition of fungi but not bacteria. Rhizosphere, 9: 18-26.

Czarnecki, O., Yang, J., Weston, D.J., Tuskan, G.A., Chen, J.-G. (2013). A dual role of strigolactones in phosphate acquisition and utilization in plants. Int. J. Mol. Sci, 14: 7681-7701

Demirbaş, S., Dinler, B.S., Önay, E. (2015). Soya Bitkisinde GR24 Ön Uygulamasının Tuz Stresinin Oluşturduğu Hasarı İyileştirmedeki Rolü. 1. Ulusal Bitki Sempozyumu, 1-4 Eylül 2015. Erzurum, Türkiye. 43 s.

Druege, U., Franken, P., Hajirezai, M.R. (2016). Plant hormone homoestasis, signalling, and function during adventitious root formation in cuttings. Fronteriers in Plant Science 7, 381.

Ferguson, B.J., Beveridge, C.A. (2009). Roles for auxin, cytokinin, and strigolactone in regulating shoot branching. Plant Physiology 149, 1929-1944.

García-Garrido, J.M., Lendzemo, V., Castellanos-Morales, V., Steinkellner, S., Vierheilig H. (2009). Strigolactones, signals for parasitic plants and arbuscular mycorrhizal fungi. Mycorrhiza, 19(7):449-459.

Gök Özel, Ş. (2018). Strigolakton Uygulamasıyla Tuz Stresine Karşı Kum Zambağı Bitkisinin Toleransının Arttırılmasında Antioksidan Enzimlerin İşlevi. Yüksek Lisans Tezi, Tekirdağ Namık Kemal Üniversitesi Fen Bilimleri Enstitüsü, Tekirdağ. $118 \mathrm{~s}$.

Gözükırmızı, N., Karlık, E. (2019). Bitki Biyoteknolojisinde Tarihsel Gelişmeler, In: (eds. Çiftci, Y.Ö., Uncuoğlu, A.A.) Bitki Biyotnolojisinde Güncel Yaklaşımlar, Palme Yayınevi, Ankara.

Kausar, F., Shahbaz, M. (2017). Influence of strigolactone (GR24) as a seed treatment on growth, gas exchange and chlorophyll fluorescence of wheat under saline conditions. International Journal of Agriculture and Biology, 19: 321

e-ISSN: 2148-2683 molekülü olarak çalışan, yeni ortaya çıkan bir bitki hormonudur. SL'lar, sinyal bileşikler olmasının yanı sıra, kuraklık, tuzluluk, mineral madde eksikliği gibi çeşitli stres koşuları altında, bitkilerde tolerans mekanizmasını uyarmakta, bu nedenle dışarıdan yapılan uygulamalarla birlikte bitki gelişimini olumlu yönde etkilediği bilinmektedir.

Kohlen, W., Charnikhova, T., Liu, Q., Bours, R., Domagalska, M.A., Beguerie, S., Verstappen, F., Leyser, O., Bouwmeester, H., Ruyter-Spira, C. (2011). Strigolactones are transported through the xylem and play a key role in shoot architectural response to phosphate deficiency in nonarbuscular mycorrhizal host Arabidopsis. Plant physiology, 155(2): 974-987.

Kopta, T., Antal, M., Jurica, M., Volkova, J., Pokluda, R. (2017). The Influence of synthetic strigolactones and plant extracts on the morphological parameters of onion (Allium cepa). Advances in Horticultural Science, 31(4):235-240.

Kumlay, M., Eryiğit, T. (2011). Bitkilerde Büyüme ve Gelişmeyi Düzenleyici Maddeler: Bitki Hormonları. Iğdır Üniversitesi Fen Bilimleri Enstitüsü Dergisi 1(2): 47-56.

Kürtür, O.B. (2018). Tuz stresine dayanıklı ve duyarlı buğday çeşitlerinde strigolakton uygulamasına fizyolojik ve biyokimyasal yanıtlar. Çanakkale Onsekiz Mart Üniversitesi, Fen Bilimleri Enstitüsü. Biyoloji Anabilim Dalı Yüksek Lisans Tezi. Çanakkale. $45 \mathrm{~s}$.

Ling, F.L., Su, Q.W., Jiang, H., Cui, J.J., He, X.L., Wu, Z.H., Zhang, Z.A., Liu, J., Zhao, Y.J. (2020). Effects of strigolactone on photosynthetic and physiological characteristics in salt-stressed rice seedlings. Sci. Rep, 10:6183

Lopez-Obando, M. Ligerot, Y., Bonhomme, S., Boyer, F., Rameau, C. (2015). Strigolactone biosynthesis and signaling in plant development. The Company of Biologists 142, 3615-3619.

Ma, N., Hu, C., Wan, L., Hu, Q., Xiong, J., Zhang, C. (2017). Strigolactones improve plant growth, photosynthesis, and alleviate oxidative stress under salinity in rapeseed (Brassica napus L.) by regulating gene expression. Front Plant Sci, 8. https ://doi.org/10.3389/fpls.2017.01671

Mashiguchi, K., Seto, Y., Yamaguchi, S. (2021). Strigolactone biosynthesis, transport and perception. Plant J, 105 (2): 335 350. https://doi/10.1111/tpj.15059

Mostofa, M.G., Rahman, M.M., Nguyen, K.H., Li, W., Watanabe, Y., Tran, C.D., Zhang, M., Itouga, M., Fujita, M., Tran, L.P. (2021). Strigolactones regulate arsenate uptake, vacuolar-sequestration and antioxidant defense responses to resist arsenic toxicity in rice roots. J Hazard Mater, 5; 415:125589.

https ://doi.org/10.1016/j.jhazmat.2021.125589.

Önay, E. (2019). Strigolaktonun tuz stresine toleranslı ve duyarlı buğday çeşitlerinde askorbat-glutatyon döngüsü enzim sistemine etkisi. Tekirdağ Namık Kemal Üniversitesi, Fen Bilimleri Enstitüsü, Tarımsal Biyoteknoloji Anabilim Dalı, Yüksek Lisans Tezi. Tekirdağ, $79 \mathrm{~s}$.

Piotrowska-Niczyporuk, A., Bajguz, A., Zambrzycka, E., Godlewska-Żyłkiewicz, B. (2012). Phytohormones as regulators of heavy metal biosorption and toxicity in green alga Chlorella vulgaris (Chlorophyceae). Plant Physiol, Biochem. 52:52-65

Qiu, C.W., Zhang, C., Wang, N.H., Mao, W., Wu, F. (2021). Strigolactone GR24 improves cadmium tolerance by regulating cadmium uptake, nitric oxide signaling and 
antioxidant metabolism in barley (Hordeum vulgare L.). Environ Pollut. 15;273:116486. https ://doi.org/10.1016/j.envpol.2021.116486.

Ruyter-Spira, C., Kohlen, W., Charnikhova, T., van Zeijl, A., van Bezouwen, L., de Ruijter, N., Cardoso, C., Lopez-Raez, J.A., Matusova, R., Bours, R., Verstappen, F., Bouwmeester, H. (2011). Physiological effects of the synthetic strigolactone analog GR24 on root system architecture in Arabidopsis: another belowground role for strigolactones? Plant Physiol, 155(2):721-34.

Saeed, W., Naseem, S., Ali, Z. (2017). Strigolactones Biosynthesis and Their Role in Abiotic Stress Resilience in Plants: A Critical Review. Front Plant Sci, 28 (8):1487.

Santoro, V., Schiavon, M., Gresta, F., Ertani, A., Cardinale, F., Sturrock, C.J., Celi, L., Schubert, A. (2020). Strigolactones Control Root System Architecture and Tip Anatomy in Solanum Lycopersicum L. Plants under P Starvation. Plants (Basel, Switzerland), 9(5): 612. https://doi.org/10.3390/plants9050612

Sarwar, Y., Shahbaz, M. (2019). GR24 triggered variations in morphophysiological attributes of sunfower (Helianthus annuus) under salinity. Int J Agric Biol, 21:34-40

Shindo, M., Nagasaka, S., Kashiwada, S., Shimomura, K., Umehara, M. (2021). Shoot has important roles in strigolactone production of rice roots under sulfur deficiency. Plant Signal Behav, 3;16(4):1880738. https ://doi.org/10.1080/15592324.2021.1880738.

Smith, S.M. (2014). Q\&A: What are strigolactones and why are they important to plants and soil microbes? BMC Biol, 12: 19. https://doi.org/10.1186/1741-7007-12-19

Tai, Z., Yin, X., Fang, Z., Shi, G., Lou, L., Cai, Q. (2017). Exogenous GR24 alleviates cadmium toxicity by reducing cadmium uptake in switchgrass (Panicum virgatum) seedlings. Int J Environ Res Public Health, 14(8):852

Takahashi, I., Asami, T. (2018). Target-based selectivity of strigolactone agonists and antagonists in plants and their potential use in agriculture. J Exp Bot, 69(9):2241-2254.

Toh, S., Kamiya, Y., Kawakami, N., Nambara, E., McCourt, P., Tsuchiya, Y. (2012). Thermoinhibition uncovers a role for strigolactones in Arabidopsis seed germination. Plant Cell Physiol, 53(1):107-17.

Ueda, H., Kusaba, M. (2015). Strigolactone Regulates Leaf Senescence in Concert with Ethylene in Arabidopsis. Plant Physiology, 169: 138-147.

Umehara, M. (2011). Strigolactone, a key regulator of nutrient allocation in plants. Plant Biotechnology, 28: 429-437.

Umehara, M., Hanada, A., Magome, H., Takeda-Kamiya, N., Yamaguchi, S. (2010). Contribution of Strigolactones to the Inhibition of Tiller Bud Outgrowth under Phosphate Deficiency in Rice. Plant and Cell Physiology, 51 (7):11181126

Umehara, M., Hanada, A., Yoshida, S., Akiyama, K., Arite, T., Takeda-Kamiya, N., Magome, H., Kamiya, Y., Shirasu, K., Yoneyama, K., Kyozuka, J., Yamaguchi, S. (2008). Inhibition of shoot branching by new terpenoid plant hormones. Nature, 455:195-200

Van Ha, C., Leyva-Gonzálezc, A., Osakabed, Y., Trana, T.U., Nishiyama, R., Watanabea, Y., Tanakae, M., Sekie, M, Yamaguchif, S., Dong, V., Yamaguchi-Shiozakig, K., Shinozakid, K., Herrera-Estrellac, L. (2014). Positive Regulatory Role of Strigolactone in Plant Responses to Drought and Salt Stress. Plant Biology, 111 (2): 851-856.
Verma, V., Ravindran, P., Kumar, P.P. (2016). Plant hormone mediated regulation of stress responses. BMC Plant Biology 16,86 .

Visentin, I., Vitali, M., Ferrero, M., Zhang, Y., Ruyter-Spira, C., Novák, O., Cardinale, F. (2016). Low Levels of Strigolactones in Roots as A Component of The Systemic Signal of Drought Stress in Tomato. New Phytologist, 212(4): 954-963.

Wang, Y., Wang, L., Yang, X., Li, X., Zang, H., Fang, B. (2021). Effects of Wheat Grain Filling and Yield Formation by Exogenous Strigolactone Under Drought Condition. Journal of Biobased Materials and Bioenergy, 15 (2): 218-223

Waters, M.T., Gutjahr, C., Bennett, T., Nelson, D.C. (2017). Strigolactone Signaling and Evolution. Annual Review of Plant Biology, 68:1: 291-322

Xie, X.N., Yoneyama, K., Yoneyama, K. (2010). The strigolactone story. Annu Rev Phytopathol, 48:93-117.

Yoneyama, K., Yoneyama, K., Takeuchi, Y., Sekimoto, H. (2007). Phosphorus deficiency in red clover promotes exudation of orobanchol, the signal for mycorrhizal symbionts and germination stimulant for root parasites. Planta, 225: 1031-1038.

Zulfiqar, H., Shahbaz, M., Ahsan, M., Nafees, M., Nadeem, H., Akram, M., Maqsood, A., Ahmar, S., Kamran, M., Alamri, S., Manzer, Siddiqui, M., Shah, Fahad, S. (2020). Strigolactone (GR24) Induced Salinity Tolerance in Sunflower (Helianthus annuus L.) by Ameliorating MorphoPhysiological and Biochemical Attributes Under In Vitro Conditions. J. Plant Growth Regul, https ://oi.org/10.1007/s00344-020-10256-4 